\title{
Palliative care needs rounds in rural residential aged care: a mixed-methods study exploring experiences and perceptions of staff and general practitioners.
}

Suzanne Rainsford, ${ }^{1,2}$ Nikki Johnston, ${ }^{2}$ Wai-Man Liu, ${ }^{3}$ Nicholas Glasgow, ${ }^{1,2}$ Liz Forbat ${ }^{4}$

1. Medical School, Australian National University, Canberra, Australia.

2. Calvary Health Care Bruce - Clare Holland House, Canberra, Australia

3. Research School of Finance, Actuarial Studies and Statistics, College of Business and Economics, Australian National University, Canberra, Australia.

4. Faculty of Social Sciences, University of Stirling, Stirling, United Kingdom

\section{Corresponding author:}

Suzanne Rainsford. Postal address: Clare Holland House, 5 Menindee Dr, Barton ACT Australia 2600. suzanne.rainsford@anu.edu.au

\section{Accepted Progress in Palliative Care 22 ${ }^{\text {nd }}$ November, 2019}

DOI: $10.1080 / 09699260.2019 .1698177$

\begin{abstract}
New approaches are needed to assist residential aged care (RAC) staff increase their skills and confidence in identifying when residents are nearing the dying phase and managing symptoms. One new evidence-based approach to improve palliative and end-of-life care in RAC is outreach Specialist Palliative Care Needs Rounds (monthly triage and risk stratification meetings hereafter Needs Rounds); as yet untried in rural settings which may face unique enablers or challenges. Needs Rounds were introduced into two RAC facilities in the rural Snowy Monaro region of New South Wales, Australia. This study explored staff and general practitioners'(GPs') experiences and perceptions of palliative and end-of-life care in rural RAC, and staff confidence and capability in providing such care, prior to, and after the introduction of Needs Rounds. A mixed-methods, pre- and post-intervention approach was taken, utilising a Likert-scale written questionnaire and face-to-face semi-structured interviews. Between March and November 2018, 61 questionnaires were completed by 48 RAC staff (33 pre-, 28 post-intervention); eight staff
\end{abstract}


and three GPs were interviewed. Despite system and site-specific barriers, staff self-reported that Needs Rounds increased their capability in providing end-of-life care $(\mathrm{p}=0.04$; $95 \%$ CI 0.20 7.66), and improved staff: (1) awareness of end of life, reflective practice, and critical thinking; (2) end-of-life decision making and planning; and (3) pain management. Needs Rounds are acceptable and feasible in rural RAC. Palliative and end-of-life care for residents may be improved through education, collaboration, communication, and planning. Further studies should explore running Needs Rounds via telehealth and/or utilising a multidisciplinary approach.

Key words: Homes for the aged; palliative care; end of life care; older persons; goals of care; needs rounds; mixed methods research

\section{Introduction}

With an aging population, and many living with multiple, complex co-morbidities, the demand for residential aged care (RAC), for people aged 65-years and over, is increasing [1-3] along with their obligation to provide high quality palliative and end-of-life care and deliver a 'safe death' [4]. RAC in rural and remote settings face unique barriers to quality palliative and end-oflife care $[5,6]$ as facilities are generally small and lack the urban economies of scale and scope, meaning options are more limited and less specialised than in the major cities $[7,8]$.

RAC staff and general practitioners (GPs) play a central role in palliative and end-of-life care within RAC; however, GPs and RAC staff frequently report their capability inadequate due to system, health care provider, and resident factors [5,9-11]. Lack of education and access to specialist palliative care services are recurring themes $[10,12,13]$, often amplified in rural settings where distance can restrict access to services, training and mentoring $[5,13,14]$.

New approaches are needed to assist staff to increase their skills and confidence in identifying when residents are nearing the dying phase and managing symptoms $[15,16]$. This 
may reduce avoidable hospital transfers at end of life, or residents remaining at the facility with symptoms less than optimally managed [17-19].

One new urban evidence-based approach is Palliative Care Needs Rounds (hereafter Needs Rounds) [20,21]. These are hour-long monthly clinical triage meetings in which RAC staff meet with an outreach specialist palliative care clinician. Utilising the Palliative Care Needs Round Checklist [22], residents without an end-of-life plan and likely to die within six months are identified by staff and potential needs discussed. Case-based education provided in Needs Rounds, improved staff confidence [23,24]. Also, outcomes for residents were improved by a reduction in length of hospital stay and the incidence of in-hospital deaths [20,21]. To date, Needs Rounds have not been implemented in a rural setting. The lack of evidence is an impediment to improving care in these settings where rural RAC residents are at an increased risk of hospitalisation compared with their urban counterparts [6].

\section{Methods}

Aims

The aims of this study were to explore:

- Staff and GPs' experiences and perceptions of palliative and end-of-life care in rural RAC prior to, and after the introduction of Needs Rounds.

- The impact of Needs Rounds on rural RAC staff confidence and capability in providing palliative and end-of-life care.

\section{Design}

This was a two-centre mixed-methods, pre-and post-intervention study conducted between March and November 2018. Qualitative and quantitative data were collected concurrently to 
optimise the sample and enhance understanding of the data [25-27]. Qualitative data were inductive and underpinned by a social constructivist epistemological stance [28].

\section{Setting}

Two RAC facilities, both not-for-profit, with a total of 112 beds (72 and 40), employing 94 clinical staff, located in Cooma, a rural town (population 6681 [29]) in south-eastern New South Wales, Australia participated in the study. In this setting, usual (palliative) care is provided by RAC staff and GPs with case-by-case one-off support by an external non-prescribing palliative care clinical nurse consultant. Residents with complex palliative care needs, beyond the expertise of the GP, may be referred to the private part-time palliative medicine specialist.

\section{The intervention}

The intervention [20] consisted of monthly onsite Needs Rounds attended by RAC staff and led by SR, a palliative medicine specialist who is also an experienced qualitative researcher. Residents, families, and GPs did not attend. Needs Rounds, previously piloted in urban RAC, were introduced as a quality improvement initiative to support staff to recognise residents' palliative (last six months of life) and end-of-life (terminal or dying phase) care needs; staff attended during normal rostered work hours. Case-based education and staff support were provided through reviewing a resident's diagnosis, current and potential symptoms, illness trajectory, current and anticipatory medications, advance care plan, and goals of care including preferred place of care and death. Recommendations, such as GP case conferencing and anticipatory prescribing for end of life, required implementation by the staff and GPs. SR's involvement did not imply ongoing clinical management unless requested by the resident's GP. Needs Rounds differed from the published pilot study which utilised a palliative care nurse practitioner rather than a medical specialist. 
Eleven Needs Rounds, lasting 30-60minutes, were delivered between April and September 2018). In total, 31 residents under the care of nine GPs were discussed (2-5 residents per Needs Round); five residents were discussed on two occasions. Eighteen RAC staff (two managers [with nursing qualifications], seven registered nurses, one enrolled nurse and eight care assistants) participated in one or more Needs Rounds.

\section{Sampling and recruitment}

Using a convenience sampling strategy, all clinical staff were invited to complete a written questionnaire prior to, and six-months after implementing Needs Rounds. Post-intervention questionnaires were available to all staff on the assumption there was a flow on effect to staff not participating in Needs Rounds. Questionnaires were distributed internally.

Qualitative interviews were conducted concurrently with a convenience sample of all clinical staff (pre-intervention) and a purposeful sample of key staff to ensure an appropriate cross-section (pre- and post-intervention). Inclusion criteria are provided in Table 1.

During the initial Needs Rounds, staff reported reticence amongst GPs to follow through on recommendations made. The protocol was amended, and all GPs $(n=9)$ attending the facilities were invited, via email, to participate in face-to-face interviews to explore their perspectives on palliative and end-of-life care in RAC.

[Table 1 near here]

\section{Data collection}

All clinical staff were invited to complete a questionnaire regarding their perceptions and knowledge of, and confidence in providing palliative and end-of-life care. The questionnaire included de-identified demographic data, a 9-item Likert scale Capability of Adopting Palliative Approach (CAPA) questionnaire [30], and the 33-item Likert scale Staff perceptions on end-oflife care in residential aged care survey [11]. CAPA required participants to rate their 
confidence, from 1 (not at all confident) to 5 (completely confident), in identifying, assessing and discussing residents' end-of-life needs, identifying and implementing appropriate management plans and interventions, and engaging specialist palliative care resources. Sections in the Staff Perceptions survey included: care of the dying, communication, teamwork, documentation, and attitudes (included one open-text question). Seventy questionnaires were available in the staffroom both pre-and post-intervention.

Interviews were conducted by SR. Pre-intervention staff interview prompts were based on the outcomes of the published urban pilot study [23] and included questions relating to current practice (pain management, advance care planning, decision-making, communication, and hospital transfers); data collection was limited by the pre-determined start-date of Needs Rounds. The post-intervention prompts were developed over the course of the study and included questions relating to changes in practice and knowledge.

GP interview prompts included experiences in providing end-of-life care in RAC, advanced care planning, case-conferencing, and anticipatory prescribing.

Interviews, lasting 10 to 40 minutes (mean 20 minutes), were audio-recorded at participants' workplaces during work hours. Active listening was utilised to confirm correct understanding; transcripts were not returned.

During data collection, SR was involved in the direct medical care of one resident. As a clinician-researcher, SR was conscious of her dual role and regularly debriefed on her clinicianresearcher role with two clinician-researchers (NJ and $\mathrm{NG)}$ to ensure that she was ethically and conscientiously maintaining role boundaries [31].

\section{Data analysis}

Data sets were analysed separately, then triangulated to test for consistency and enhance validity. 
Questionnaire data management and analyses were executed in STATA 14.1 statistical software (StataCorp LP, College Station, TX). Incomplete questionnaires were excluded. RAC staff data were controlled for individual heterogeneity in their capability to learn/re-learn/adopt new tools in their care. We report the regression coefficient (impact on CAPA scores) of the post-Needs Rounds effect. A mean score was calculated for each question in the Staff Perceptions surveys - the lower the mean the more confident or better skilled. A 5\% level of significance $(\mathrm{p} \leq 0.05)$ was used for all tests. Responses to the single free text question were amalgamated with interview data.

Interviews were transcribed verbatim, coded, and analysed thematically [32]. SR and NJ independently read the transcripts to become familiar with the data. A thematic framework was constructed after comparing and discussing ideas. Coding was inductive [32]. Utilising a whiteboard, discussions continued until agreement was reached on identification, grouping and labelling of distinct themes and subthemes. To manage data storage, data were then entered into NVivo-11.

\section{Ethical issues}

This study was approved by the Australian National University Human Research Ethics Committee (2017/933).

\section{Results}

\section{Questionnaires}

Forty-eight staff returned 61 questionnaires (33 pre-intervention and 28 post-intervention); 13 staff completed both questionnaires (Table 2). Respondents were mostly female $(n=54 ; 89 \%)$; average age 47years (range 18 - 69years); and average time working in RAC was 10years (range 3 months - 30years). 
[Table 2 near here]

Of the 61 questionnaires returned, two CAPA (3\%) were incomplete and therefore discarded. Twenty-two (36\%) Staff Perceptions surveys were incomplete and excluded from the analysis. CAPA data analysis showed statistically significant improvements in staff self-reported knowledge and confidence in identifying, assessing, discussing, and managing end-of-life care (Table 3). Likewise, analysis of the Staff Perceptions survey demonstrated statistically significant improvements in staff feeling that goals of care are achievable (Q14) and knowledge on how to access specialist palliative care (Q28). After the intervention, there was trend towards improved care of the dying, communication, and team work; however, the improvements were not statistically significant (Figure 1).

[Table 3 near here]

[Figure 1 near here]

\section{Interviews}

Fourteen interviews were conducted with 11 participants. RAC participants had worked at their facility for a median of 6.5 years (range 1 - 15 years), and had worked in the RAC sector for a median of 19.5 years (range 1- 30 years). All GPs had worked in Cooma for over 12 years (Table 4).

[Table 4 near here]

\section{Experiences and perceptions prior to Needs Rounds}

Consistent with the interpretation of the pre-intervention questionnaires, staff felt confident in the care provided. Staff felt they were caring and that pain management and 'personal basic care [was done] well' (M1), as was mouth, pressure area and skin care. Some staff struggled when 'something sudden happened' (CA2). While it was often 'difficult to know if [deterioration] is actually the beginning of a terminal phase or just a cold' (GP3), once the 
terminal phase was recognised, staff and GPs felt confident in managing pain with a syringe driver.

Some staff described having 'really, really good relationship with all of the GPs' (RN3), others felt that communication with GPs wasn't 'working really well' (RN2). Staff had access to GPs working in the hospital emergency department. When unable to leave the hospital, some GPs requested the resident be transferred to hospital to expedite a medical review. On occasions, 'the on-call doctor at the hospital can do a phone order' (M1) and has even 'personally delivered [medication] to us from the hospital' (M2).

Existing formal and informal relationships between health providers were a feature of this rural setting and facilitated sharing of resources:

There was the time we lost two residents in the one day and I ended up needing two syringe drivers, so I got one off [community health] and one off the [other] nursing home.... just having those contacts, which is handy and good support. (M2)

Participants acknowledged barriers to providing quality end-of-life care. Workforce factors (shortages, high turnover, inexperience, and availability of GPs) were of concern, sometimes resulting in residents being transferred to hospital:

There's only one nurse on and they're flat out. They're looking after 60 people. It's just easier [to send the resident to hospital], rather than try and sort out what's been going on. (GP2) 
An individual person might not have the skills, expertise, training, experience to provide that care ... it's a shift by shift thing... And I think that sometimes we, [medical staff] for whatever reason, are not available enough to provide that level of support. (GP3)

Sometimes the doctors are not very supportive, but then they're time poor. (RN2)

Poor communication, handover, and team work were reported:

I thought that the facility was on board but then the shift changes and then the people that you've talked to are away for a while, they don't refer back to plans, suggestions and recommendations. They don't pass it on effectively and it just gets a bit lost. (GP3)

I get along well with all the GPs, but some of them don't acknowledge that we may be able to contribute. They need to take a step back and rely upon what we're telling them, instead of questioning everything. (RN4)

One GP felt that current accreditation requirements impacted negatively on resident care:

I think there's been an excessive turn towards [paper work] and an excessive risk aversion. And this applies more widely in terms of restricting residents' autonomy because of an excessive focus on safety over autonomy. (GP1)

Resident and family factors also impacted care. One GP acknowledged the challenge of predicting disease trajectories, especially of non-malignant conditions: 
I've probably delayed definitive management because of that concern in the past... is it appropriate to write up medications presumptively if you're not sure, if you don't know? (GP3)

Inadequate advance care planning, ambiguous goals of care, and conflict within families, and between families and health care providers created challenges to care:

Something that we don't do well is having those back up orders for pain relief. Sometimes it can be a bit of rush to try and get on the phone to a doctor to try and get a medication order. (RN3)

I think sometimes residents have been transferred to hospital when they haven't really needed to go, but because the communication hadn't been clear enough that they're for management here and not for hospital transfer. (RN2)

The family had a view, the facility staff had a view, I had a view... it was just a bit hard to bring all of those together. (GP3)

Staff and GPs were open to change and supported the concept of Needs Rounds, 'anything we can do to make it a better process for everybody would be a good thing'. (M1)

\section{Experiences and perceptions after Needs Rounds}

After data analysis, three key themes described the impact of Needs Rounds. 
Theme 1: Needs Rounds strengthened awareness of end of life, reflective practice, and critical thinking by rural health care providers. Prior to Needs Rounds, most staff reported confidence in identifying a dying resident, assessing and managing symptoms, and discussing death and dying with relatives:

I've been here for quite a number of years and seen lots of people enter that stage of life and everyone's different when they're approaching. So, I think I'm quite confident in recognising the signs and symptoms. (RN3)

Needs Rounds provided opportunity for staff to reflect on their current practice. Gaps in knowledge and skills became apparent. RN3 (above) became aware of aspects of care, especially planning for predictable events, not previously considered:

I think it was really good just going through [the residents'] folders and their diagnosis, and you picking up [missing advance care plans] and things that we hadn't thought about...One man I brought up in the Needs Rounds had seizures, and you asked, "What are you going to do if the seizure doesn't stop?" We hadn't thought of that. So just thinking outside the square about different things that can happen, and recognising them early. (RN3)

The education component of Needs Rounds was acknowledged by staff. Due to travel distances, and work and family commitments, these rural participants were unable to attend outof-town education, as 'the palliative care training just doesn't fit in with me at the moment' (GP2). While GPs did not attend Needs Rounds they were supportive of the concept: 
That meeting that you have with the nursing home as a palliative care specialist, it would be good as a GP to be involved to see what you're doing 'cause we learn a lot from what you do. You think "oh yes, I could have done that." (GP2)

With an opportunity to reflect and a willingness to change, staff were enabled to provide greater individualised and person-centred care:

I've assessed patients in a different way... it's had me look more in depth at the resident. (RN1)

Theme 2: Needs Rounds strengthened decision making and planning at end of life. Reviewing health records during Needs Rounds provided opportunity to check that advance care plans were unambiguous and up to date ahead of time and not during a medical emergency and facilitated a collaborative approach to decision-making:

I felt it was informative and having your expertise, just to throw ideas around, was a good thing. Prior to that we didn't really discuss it as a group. It was made by the $R N$, who may have spoken to the GP... But to get different opinions was collaborative. Like the way it should be. (M1)

Prior to Needs Rounds, staff spoke of the need for 'Everybody to be on board... to be at the same spot at the same time' (RN4). Case-based discussions enabled scenarios to be personalised, thus encouraging the staff to anticipate events. This increased the confidence of staff to initiate what were previously difficult conversations with residents, families and GPs: 
I think I feel more comfortable or able to bring it up [with relatives], than I did in the past...just to have a little bit more information we may have learned or gathered. (M1)

The nurses also gained confidence in approaching GPs to ask questions and make suggestions:

I didn't realise that you could say to the GP, "can we have this medication, just in case this happens?" ... And I think certain doctors appreciate that you're trying to be prepared for those situations in the middle of the night. (RN3)

Each facility had their own preferred advance care planning paperwork. While important that documentation contained concise information about a person's health status, treatment choices and medical decisions, staff were encouraged to consider resident and family wishes in broader terms, such as spiritual care:

Advance care directives are more than just 'no CPR' ... it's not box ticking it's ... quality of life and what's important to you...sometimes it will be antibiotics and sometime it's not. (GP2)

Participants acknowledged that flexibility was required when actioning a documented advance care plan and that occasionally there were legitimate reasons for altering what had previously been agreed:

If there's some aspect of their care that cannot be manage at the nursing home, it's whatever the place is that's best for the patient. (GP3) 
Theme 3: Needs Rounds strengthened pain management at end of life. Prior to Needs Rounds, staff acknowledged that at times they lacked the expertise or resources to manage symptoms requiring specialist 'higher level care'. (M1). This contributed to symptoms not being well managed or residents being transferred to hospital. Needs Rounds strengthened pain management by increasing skills of staff in identifying and assessing pain, and confidence in approaching GPs:

I think we're just more aware that the person's in pain. Whether they can verbalise it or not, you can see it. And we need to jump on top of it quicker. Or maybe quicker than we did in the past. (M1)

However, despite strong working relationships, nurses voiced their ongoing frustration with some GPs. This was also observed in subsequent Needs Rounds where suggestions regarding anticipatory medications were often not taken up by GPs:

I think at times, and I've seen it here, the registered nurses can struggle with doctors to get the, for what they feel, is the appropriate pain relief to what the doctor feels is the appropriate pain relief. Whether they're on the same page or not, sometimes I don't think they are. (M1)

As is common in rural settings, there is no after-hours pharmacy, therefore, planning was required to ensure effective and safe medications were available when needed. Planning for anticipatory medications was a complex process involving prescribing, charting, dispensing, and 
storage of appropriate drugs in anticipation of an acute event. While one GP was not opposed to anticipatory prescribing, she:

Just hadn't thought of it .... I've never prescribed just in case... I can see the benefit of it, you know to say this patient could die any time in the event of distress or whatever then yeah this is what they can be prescribed until I'm able to review them. (GP3)

\section{Discussion}

This study reports, through the experiences and perceptions of RAC staff and GPs, the impact of introducing Palliative Care Needs Rounds into two rural RAC facilities. Needs Rounds proved acceptable and feasible. Outcomes were consistent across the mixed-methods data. The selfreported increase in staff confidence and capability was consistent with the urban pilot and subsequent INSPIRE study $[21,23,24]$ and align with strengthening of reflective practice, death literacy (confidence and knowledge in identifying, assessing, discussing and managing end-oflife care) $[23,33]$ and critical thinking [34]. Confidence in achieving goals of care and accessing specialist support was increased. The upward trends towards improved teamwork and communication were supported by the interview data. While Needs Rounds did not address all reported barriers, they allowed staff opportunity to reflect on current practice. Case-based education addressed gaps in knowledge and skills [10,35]. With increased confidence, staff felt empowered to communicate more efficiently with colleagues, residents, families, GPs and specialists to collaboratively plan for residents' end-of-life care [23,24].

This study adds a rural perspective on Palliative Care Needs Rounds in RAC. Identified barriers are analogous to those of previous studies, including those with an urban focus $[5,12,13]$; however, rural locations are often more vulnerable due to a limited 'pool' of casual 
staff and the added burden of distance in accessing specialist support, mentoring and education $[9,14,36]$.

Consistent with a previous study [11], and despite reduced resources and education opportunities, staff initially reported a high, and possibly over-estimated, level of confidence regarding their care of the dying. This may account for the lack of statistically significant improvement in the staff perception surveys (Figure1). The reported gaps in knowledge and skills are consistent with the urban pilot study [23] and similar to those reported by Landers et al. [13]. The presence of a specialist palliative care clinician leading case-based education provided convenient on-site opportunity to address the gaps and facilitate change [35].

Anticipatory medications have the potential to improve a resident's quality of life [37] and reduce hospital transfers $[18,38]$ especially in rural areas lacking after-hours pharmacies. Needs Rounds provided in-house educational opportunities for nurses regarding anticipatory medications; however, some GPs remained reticent to prescribe [39].

Transfer to hospital from RAC can be inappropriate, avoidable, burdensome [19] and disruptive to continuity of care [40]. However, in this rural setting, medical cover in the local hospital is provided by GPs, and often the resident remains the responsibility of their GP regardless of place of care. Potentially, the resident has the same GP in RAC and in the emergency department, during the week and after hours. Unlike some urban settings, the decision to transfer to hospital was at times viewed as appropriate care rather than a system failure, and frequently occurred at the request of the GP who was unable to leave their private rooms or emergency department in a timely fashion. Providing rural dwellers remain in their community, the preferred place of care and death is the 'safe' place, wherever that may be, including the local hospital [4].

Needs Rounds are an effective 'triage' tool for rural RAC staff to identify those residents at greatest risk of dying without an end-of-life plan in place. While the integration of specialist 
palliative care improves education, communication, co-ordination, and planning $[21,23,41,42]$, due to limited resources and current funding models that cross State and Commonwealth Government jurisdictions, not all rural RAC facilities have direct access to specialist palliative care clinicians available to attend Needs Rounds. Further studies are needed to determine best practice for providing specialist palliative care to rural RAC residents, particularly exploring a telehealth Needs Rounds approach from outreach urban specialist services [16,43]. A multidisciplinary care planning approach may also be more effective in engaging GPs [10]. Finally, while the educational outcome was significant for RAC staff, for sustainability of the model a financial assessment is required as this study was reliant on the good will of the specialist for whom remuneration was not possible without formal referral from the GP $[9,16]$.

\section{Strengths and Limitations}

Our sample comprised GPs and a cross-section of RAC staff. While the sample was small, response rate low, and a high rate of incomplete questionnaires, the data are enriched by the mixed-methods approach. Data saturation is unlikely but interview and questionnaire data are consistent. The results may not be generalisable to all rural locations, or even those of comparable populations, and are unlikely to reflect the experiences of those living in remote regions [44]. The data are self-reported and may not accurately reflect practice; resident and family voices are absent.

The researcher's dual role as clinician and researcher, and prior knowledge of the facilities and some participants is a limitation (potential for bias and recruitment coercion), but also a strength [31]. It is possible that any measurable effect may be due to the personality and familiarity of the researcher rather than the intervention. However, the results are comparable to the published urban studies [23,24], suggesting the positive effects were due to the Needs Rounds. 


\section{Conclusion}

Needs Rounds were acceptable and feasible in rural RAC and facilitated improved self-reported staff confidence and capability. Palliative and end-of-life care for residents may be improved through education, collaboration, communication, and planning. Further studies are needed to explore running Needs Rounds via telehealth and/or utilising a multidisciplinary approach to include GPs.

\section{Funding}

The authors received no financial support for the research, authorship, and/or publication of this article.

\section{Conflict of interest}

The authors declare that there is no conflict of interest.

\section{Authors' contribution}

SR, NJ, NG, WL, and LF designed the study. SR collected the data. SR and NJ analysed the qualitative data; WL provided statistical advice. SR drafted and revised the manuscript. All authors reviewed the article critically for important intellectual content, and approved the near final version to be published. 


\section{References}

1. Pivodic L, Pardon K, Morin L, et al. Place of death in the population dying from diseases indicative of palliative care need: a cross-national population-level study in 14 countries. $J$ Epidemiol Community Health 2016; 70: 17-24.

2. Broad JB, Gott M, Kim H, et al. Where do people die? An international comparison of the percentages of deaths occurring in hospital and residential aged care settings in 45 populations, using published and available statistics. Int J Public Health 2013; 58: 257-267.

3. Bone AE, Gomes B, Etkind $\mathrm{SN}$ et al. What is the impact of population ageing on future provision of end-of-life care? Population based projections of place of death. Palliat Med 2018; 32: 329336.

4. Rainsford S, Phillips CB, Glasgow NJ, et al. The 'safe death': An ethnographic study exploring the perspectives of rural palliative care patients and family caregivers. Palliat Med 2018; 32(10):1575-1583.

5. Mitchell G, Nicholson C, McDonald K et al. Enhancing palliative care in rural Australia: The residential aged care setting. Aust J Primary Health 2011; 17: 95-101.

6. Temkin- Greener H, Zheng NT, Mukamel DB. Rural-urban differences in end-of-life nursing home care: facility and environmental factors. Gerontologist 2012; 52(3): 335-344.

7. Baldwin R, Stephens M, Sharp D, et al. Aged and Community Services Australia. Issues facing aged care services in rural and remote Australia.

https://www.parliament.nsw.gov.au/lcdocs/other/9768/Issues\%20facing\%20aged\%20care\%20ser vices\%20in\%20rural\%20and\%20remote\%20Australia.pdf (2013, accessed 25 April 2019).

8. Aged \& Community Services Australia and the National Rural Health Alliance. Older People and Aged Care in Rural, Regional and Remote Australia: A Discussion Paper June 2004.

https://www.pc.gov.au/inquiries/completed/ageing/submissions/national rural health alliance in c./sub012.pdf

9. Ding J, Saunders C, Cook A et al. End-of-life care in rural general practice: how best to support commitment and meet challenges? BMC Palliat Care 2019;18:51 doi: 10.1186/s12904-019-04354.

10. Phillips J, Davidson PM and Willcock S. An insight into the delivery of a palliative approach in residential aged care: The general practitioner perspective. J Applied Gerontology 2009; 28(3): 395-405.

11. Marshall B, Clark J, Sheward K, et al. Staff perceptions of end-of-life care in aged residential care: A New Zealand perspective. J Palliat Med 2011; 14(6): 688-695.

12. Seymour JE, Kumar A and Froggatt. K. Do nursing homes for older people have the support they need to provide end-of-life care? A mixed methods enquiry in England. Palliat Med 2010; 25(2): $125-138$.

13. Landers A, Dawson D and Doolan-Noble F. Evaluating a model of delivering specialist palliative care services in rural New Zealand. J Prim Health Care 2018; 10(2): 125-131.

14. Robinson C, Pesut B and Bottorff J. Issues in rural palliative care: views from the countryside. $J$ Rural Health 2010; 26(1): 78-84. 
15. Codde J, Frankel J, Arendts G et al. Quantification of the proportion of transfers from residential aged care facilities to the emergency department that could be avoided through improved primary care services. Australas J Ageing 2010; 29(4): 167-171.

16. Bakitas MA, Elk R, Astin M et al. Systematic Review of Palliative Care in the Rural Setting. Cancer Control 2015; 22(4): 450-464.

17. Pivodic L, Smets T, Van den Noortgate N, et al. Quality of dying and quality of end-of-life care of nursing home residents in six countries: An epidemiological study. Palliat Med 2018; 32: 1584-1595.

18. Arendts G, Quine S and Howard K. Decision to transfer to an emergency department from residential aged care: A systematic review of qualitative research. Geriatr Gerontol Int 2013; 13: $825-833$.

19. Dwyer R, Stoelwinder J, Gabbe B et al. Unplanned transfer to emergency departments for frail elderly residents of aged care facilities: A review of patient and organizational factors. J Am Med Dir Assoc 2015;16(7): 551-62.

20. Chapman M, Johnston N, Lovell C, et al. Avoiding costly hospitalisation at end of life: Findings from a specialist palliative care pilot in residential care for older adults. BMJ Support Palliat Care 2018; 8(1): 102-109.

21. Forbat L, Liu WM, Lam L, et al. Integrating specialist palliative care into residential care for older people: a stepped wedge trial (INSPIRED trial). Final report. Canberra: Australian Catholic University; 2018.

22. Forbat L, Chapman M, Lovell $\mathrm{C}$ et al. Improving specialist palliative care in residential care for older people: a checklist to guide practice. BMJ Support Palliat Care 2018; 8: 347-353.

23. Johnston N, Lovell C, Liu W, et al. Normalising and planning for death in residential care: findings from a qualitative focus group study of a specialist palliative care intervention. BMJ Support Palliat Care 2019; 9: e12.

24. Liu W-M, Koerner J, Lam L, et al. Improved quality of death and dying in care homes: A palliative care stepped wedge randomized control trial. J Am Geriatr Soc online 4 Nov 2019. https://doi.org/10.1111/jgs.16192

25. Onwuegbuzie AJ, Leech NL. Linking Research Questions to Mixed Methods Data Analysis Procedures 1.The Qualitative Report, 2006;11(3):474-498. Retrieved from https://nsuworks.nova.edu/tqr/vol11/iss $3 / 3$

26. Leech NL, Onwuegbuzie AJ. Guidelines for conducting and reporting mixed research in the field of counselling and beyond. J Counsel Development 2010: 88:61-70.

27. Farquhar M, Ewing G, Booth S. Using mixed methods to develop and evaluate complex interventions in palliative care research. Palliat Med 2011;25(8):748-757.

28. Crotty M. The foundations of social research: Meaning and perspective in the research process. London, Thousand Oaks, California: Sage Publications; 1998. Chapter 3, Constructionism: the making of meaning; p. 42-65. 
29. Australian Bureau of Statistics. 2016 Census QuickStats, Cooma (NSW).

http://quickstats.censusdata.abs.gov.au/census_services/getproduct/census/2016/quickstat/SSC11 036. (Accessed 25 March 2019).

30. The Program of Experience in the Palliative Approach (PEPA) project team (2016). [Measuring the capability of adopting palliative approach in non-specialist palliative care providers: scale development and initial psychometrics]. Unpublished data.

31. Rainsford S, Phillips C. 'An interview is not a consultation': the dual role of clinician-researcher. Lessons from an ethnographic study exploring rural patients' and family caregivers' perspectives on the 'good death'. Paper presented at: Research, $22^{\text {nd }}$ International Congress on Palliative Care; 2018 Oct 2-5; Montreal, Canada.

32. Patton, MQ. Qualitative research and evaluation methods, 3rd ed. Thousand Oaks, California: Sage Publication, 2002.

33. Nolan MM, Davies $\mathrm{S}$, Brown $\mathrm{J}$ et al. The role of education and training in achieving change in care homes: a literature review. J Res Nurs 2008; 13(5): 411-433.

34. Papathanasiou IV, Kleisiaris CF, Fradelos EC et al. Critical thinking: The development of an essential skill for nursing students. Acta Inform Med 2014; 22(4): 283-286.

35. Kinley J, Preston N and Froggatt K. Facilitation of an end-of-life care programme into practice within UK nursing care homes; a mixed methods study. Int J Nurs Stud 2018, 82: 1-10.

36. Farmer J, Munoz S and Threlkeld G. Theory in rural health. Aust J Rural Health 2012; 20: 185189.

37. Finucane AM, Stevenson B, Gardner $\mathrm{H}$ et al. Anticipatory prescribing at the end of life in Lothian care homes. Br J Community Nurs. 2014; 19(11): 544-7.

38. Lopez RP, Mitchell SL and Givens JL. Preventing burdensome transitions of nursing home residents with advanced dementia: It's more than advance directives. J Palliat Med 2017; 20(11): 1205-09.

39. Khalil H, Poon P, Byrne A et al. Challenges associated with anticipatory medications in rural and remote settings. J Palliat Med 2019; 22(03): 297-301.

40. Hullick C, Conway J, Higgins I et al. Emergency department transfers and hospital admissions from residential aged care facilities: a controlled pre-post design study. BMC Geriatr 2016; 16 : 102. doi: 10.1186/s12877-016-0279-1

41. Cox A, Arber A, Bailey F et al. Developing, implementing and evaluating an end of life care intervention. Nursing Older People. 2017; 29(1): 27-35.

42. Luckett T, Phillips J, Agar M, et al. Elements of effective palliative care models: a rapid review. BMC Health Serv Res. 2014; 14:136 pp1-22. doi: 10.1186/1472-6963-14-136.

43. Mills J. Digital health technology in palliative care: Friend or foe? Prog Palliat Care 2019; 17: 145-146.

44. Menec VH Menec, S Nowicki, A Kalischuk. Transfers to acute care hospitals at the end of life: do rural/remote regions differ from urban regions? Rural and Remote Health 2010; 10:1281. (Online). 
Table 1 Pre- and post- intervention inclusion criteria

\begin{tabular}{|c|c|c|c|c|}
\hline & $\begin{array}{l}\text { Pre- and post- } \\
\text { intervention written } \\
\text { questionnaire }\end{array}$ & $\begin{array}{l}\text { Pre-Needs Rounds } \\
\text { RAC staff interview }\end{array}$ & $\begin{array}{l}\text { Post-Needs Rounds } \\
\text { RAC staff interview }\end{array}$ & $\begin{array}{l}\text { General } \\
\text { Practitioners' } \\
\text { interview }\end{array}$ \\
\hline $\begin{array}{l}\text { Inclusion } \\
\text { criteria }\end{array}$ & $\begin{array}{l}\text { - Any staff member } \\
\text { directly involved } \\
\text { in clinical } \\
\text { management } \\
\text { and/or } \\
\text { personal care } \\
\text { - } 18 \text { years of age or } \\
\text { older } \\
\text { - Understands } \\
\text { written English } \\
\text { - Worked in RAC } \\
\text { sector } \geq 3 \text { months* } \\
\text { - Consent implied } \\
\text { by return of } \\
\text { questionnaire }\end{array}$ & $\begin{array}{l}\text { - } 18 \text { years of age or } \\
\text { older } \\
\text { - English speaking } \\
\text { - Worked in RAC } \\
\text { sector } \geq 3 \\
\text { months.* } \\
\text { - Written informed } \\
\text { consent }\end{array}$ & $\begin{array}{l}\text { - Participated in at } \\
\text { least one needs } \\
\text { round } \\
\text { - } 18 \text { years of age or } \\
\text { older } \\
\text { - English speaking } \\
\text { - Written informed } \\
\text { consent }\end{array}$ & $\begin{array}{l}\text { - Currently caring } \\
\text { for one or more } \\
\text { resident at the } \\
\text { participating } \\
\text { RAC facilities. } \\
\text { - Written informed } \\
\text { consent }\end{array}$ \\
\hline
\end{tabular}

Table 2 Role of staff completing the Capability of Adopting Palliative Care (CAPA) ${ }^{30}$ questionnaire

\begin{tabular}{lcc}
\hline Role & $\begin{array}{c}\text { Pre-Needs } \\
\text { Rounds } \\
\mathrm{n}=33\end{array}$ & $\begin{array}{c}\text { Post Need-Rounds } \\
\mathrm{n}=28\end{array}$ \\
\hline Registered nurse & 9 & 9 \\
Enrolled nurse & 2 & 2 \\
Care assistant & 17 & 17 \\
Activities co-ordinator & 1 & 0 \\
Unknown & 4 & 0 \\
\hline
\end{tabular}


Table 3 Staff Questionnaire - Capability of Adopting Palliative Approach (CAPA) scores

CAPA scores (Sum of Q1-Q9) $)^{\text {II }}$

\begin{tabular}{cc|ccc}
\hline Pre-Needs Rounds & Post-Needs Rounds & Impact of & & \\
Unadj. mean (SD) & Unadj. mean (SD) & Needs Round* & CI & $p$-value \\
$29.5(8.2)$ & $33.9(7.3)$ & 3.93 & $0.20-7.66$ & 0.04 \\
& & & 59 & \\
& & & 0.21 & \\
& & & & \\
\end{tabular}

"Original sample size is 61.2 were excluded due to incomplete questionnaires.

${ }^{\S}$ Responses to a 5 -point Likert scale $(0=$ not at all confident and $5=$ completely confident $) .{ }^{28}$

* Regression adjusted for the respondent's years in RAC and their roles. Role $=1$ if the survey respondent is a care assistant, 2 if s/he is a registered nurse, and 3 for others or missing. Results remain unchanged when the variable Role is removed from the regression. Robust standard error clustered at the facility level. 
Table 4 Pre- and post- Needs Rounds interview participants

\begin{tabular}{|c|c|c|c|c|c|c|c|c|}
\hline Participant & Role & Sex & Age & $\begin{array}{l}\text { Years } \\
\text { at } \\
\text { current } \\
\text { facility }\end{array}$ & $\begin{array}{l}\text { Years } \\
\text { in } \\
\text { RAC } \\
\text { sector }\end{array}$ & $\begin{array}{l}\text { Pre-NR } \\
\text { interview }\end{array}$ & $\begin{array}{l}\text { Post-NR } \\
\text { interview }\end{array}$ & $\begin{array}{l}\text { NRs } \\
\text { attended }\end{array}$ \\
\hline M1 & Manager & Male & 50 & 5 & 30 & $\checkmark$ & $\checkmark$ & 4 \\
\hline M2 & Manager & $\mathrm{F}$ & 43 & 15 & 25 & $\checkmark$ & & 3 \\
\hline RN1 & RN & $\mathrm{F}$ & 60 & 10 & 12 & - & $\checkmark$ & 4 \\
\hline RN2 & RN & $\mathrm{F}$ & 64 & 4 & 29 & $\checkmark$ & - & 1 \\
\hline RN3 & RN & $\mathrm{F}$ & 28 & 8 & 8 & $\checkmark$ & $\checkmark$ & 6 \\
\hline RN4 & $\mathrm{RN}$ & F & 65 & $<1$ & 27 & $\checkmark$ & $\checkmark$ & 1 \\
\hline CA1 & $\mathrm{CA}$ & $\mathrm{F}$ & 52 & 14 & 14 & $\checkmark$ & - & 0 \\
\hline $\mathrm{CA} 2$ & CA & $\mathrm{F}$ & 49 & 1 & 1 & $\checkmark$ & - & 0 \\
\hline GP1 & GP & $\mathrm{F}$ & 50 & $>12$ & NA & $\checkmark$ & - & 0 \\
\hline GP2 & GP & $\mathrm{F}$ & 52 & $>12$ & NA & $\checkmark$ & - & 0 \\
\hline GP3 & GP & Male & 53 & $>12$ & NA & $\checkmark$ & - & 0 \\
\hline
\end{tabular}

